\title{
TRANSFORMAÇÃO DA FILOSOFIA: COMPLEMENTARIDADE ENTRE O GIRO HERMENÊUTICO-LINGUÍSTICO E 0 PRAGMÁTICO-SEMIÓTICO
}

\author{
Antonio Wardison C. Silva*
}

\begin{abstract}
RESUMO
O artigo apresenta as principais características da transformação da filosofia transcendental, chamada por Apel de pragmático-transcendental. Esta tarefa foi possibilitada pela complementaridade entre o giro hermenêutico-linguístico, baseado em Heidegger e Gadamer, e o giro pragmático-semiótico, fundado em Peirce. Com isso, Apel institui a superação da filosofia solipsista e a constituição de uma filosofia intersubjetiva, fundada pela linguagem, em busca da verdade e validação das proposições tomadas em consenso pela comunidade ilimitada de comunicação.
\end{abstract}

Palavras-chave: Transcendental. Linguagem. Hermenêutica. Semiótica.

\begin{abstract}
This paper presents the main features of the transformation of transcendental philosophy called as pragmatic-transcendental by Apel. This task was made possible by the complementarity between the linguistic-hermeneutic turn, based on Heidegger and Gadamer, and pragmatic-semiotic turn, established on Peirce. Thus, Apel establishes the overcoming of the solipsistic philosophy and constitutes an intersubjective philosophy, founded on the language, searching the truth and validation of the propositions taken by consensus of the unlimited communication community.
\end{abstract}

Keywords: Transcendental. Language. Hermeneutics. Semiotics. * Mestrando em Filosofia pela PUCSP. Graduado em Filosofia e em Teologia. Especialista
(lato sensu) em Filosofia Existencial e em Psicopedagogia. 


\section{INTRODUÇÃO}

Para Karl-Otto Apel, a complementaridade entre o giro hermenêutico-linguístico e o giro pragmático-semiótico possibilitou a transformação da filosofia transcendental, como promotora de uma nova filosofia capaz de, ao superar o solipsismo e o dogmatismo, "se autojustificar como instância crítica de validação, ou seja, como instância transcendental de toda a pretensão de sentido".

Esta nova filosofia, chamada por Apel de "pragmático-transcendental", não somente procura superar a filosofia transcendental da consciência, mas a prima filosofia, isto é, a metafísica e a ontologia (aristotélica) e a filosofia da consciência no sentido kantiano. Ao superar essas duas fazes, pelo viés semiótico, Apel inaugura um terceiro paradigma da filosofia: a constituição de uma filosofia transcendental, portadora de linguagem, como medium de todo entendimento.

Ora, a construção deste novo paradigma é fruto da contribuição de algumas correntes filosóficas, incorporadas e superadas por Apel. Por isso, o seu pensamento constitui-se como uma reflexão crítica que, ao conservar alguns elementos da filosofia tradicional, procura ultrapassar o seu estatuto epistemológico na tentativa de visualizar um novo horizonte da racionalidade e investigação filosófica. Apel parte de Heidegger e Gadamer, ao considerar as hermenêuticas da pré-compreensão e da linguagem, e de Peirce, por incorporar a lógica da investigação fundamentada na dimensão sígnica (triádica), ${ }^{2}$ para arquitetar uma filosofia transcendental, de caráter pragmático-intersubjetivo, com pretensão de validade universal, dada pelo consenso.

\section{O GIRO HERMENÊUTICO-LINGUÍSTICO}

Segundo Apel, o pensamento hermenêutico de Heidegger tem um papel fundamental no contexto da transformação da filosofia: a descoberta de uma pré-estrutura da problemática da verdade, realidade tal que precede toda compreensão subjetiva, ou seja, o ser humano, concebido como Dasein (ser-no-mundo), tem uma compreensão antecipadora, explicitada na

COSTA, Regenaldo da. Ética do Discurso e Verdade em Apel, p. 155.

2 Ibid., p. 156. 
ideia de ser. Neste sentido, a verdade refere-se ao Dasein e, por isso, os sujeitos devem conceber esta condição. Há uma radicalidade em pressupor o Dasein para se pensar a verdade das coisas: "compreender não é um dos modos de agir do sujeito, mas sim o modo de ser do próprio ser-aí". ${ }^{3}$

Apel assimila de Heidegger a ideia que a verdade não está, em primeiro lugar, regida por uma representação sígnico-lógica de feitos dados no mundo, mas da interpretação do mundo, segundo as situações mais significativas para o homem. ${ }^{4}$ Não obstante, para Apel, Heidegger não imprime uma nova compreensão de verdade, mas amplia a problemática fenomenológica sobre a verdade. ${ }^{5}$ Ora, o ser-aí, que antecipa a compreensão subjetiva, não se constitui como verdade, mas pré-julgamento da possibilidade de verdade ou não verdade. Sob este ponto, afirma Apel, Heidegger não trouxe geniais contribuições quanto ao problema da verdade e sua validação. ${ }^{6}$ Ainda mais, para Apel não é possível, como Heidegger afirma, separar o problema da constituição da verdade do problema da verdade, ou seja, não se deve separar a pergunta pelas condições de possibilidades de compreensão da pergunta pela validade da verdade. Portanto, segundo Apel, "uma filosofia transcendental transformada deverá dar conta da problemática da verdade não só vinculada à historicidade da pré-compreensão, mas também vinculada à problemática da validade". ${ }^{7}$

Apel recorda que o último Heidegger recorreu aos acontecimentos históricos de sentido para falar de uma pré-compreensão de mundo, configurada por uma interpretação aberta do ser-aí. Este postulado representa o ponto central para a filosofia transcendental, na sua tentativa de superação, à medida que recusa uma compreensão subordinada ao destino do ser (esta crença pode alienar toda compreensão de sentido).

A partir de Heidegger, Apel também reflete o questionamento de Gadamer sobre a possibilidade de compreensão: como é possível a compreensão? Este questionamento é fundamental para a filosofia transcendental que se põe a refletir a pré-estrutura de todas as formas de conhecimento. Pois, para

\footnotetext{
APEL, Karl-Otto. Transformação da Filosofia I, p. 44.

HABERMAS, Jürgen. Um maestro con sensibilidad hermenêutica, p. 21.

COSTA, Regenaldo da. Ética do Discurso e Verdade em Apel, p. 37.

APEL, Karl-Otto. Transformação da Filosofia I, p. 41.

COSTA, Regenaldo da. Ética do Discurso e Verdade em Apel, p. 38.
} 
Apel, a pergunta sobre a possibilidade de compreensão implica no questionamento sobre a validade do compreender. ${ }^{8}$ Para Gadamer, segundo Apel, os pré-juízos dos intérpretes não estão disponíveis a eles e, por isso, não conseguem distingui-los, por si mesmos. Somente a hermenêutica poderá cumprir tal tarefa, que requer uma mediação entre o presente e o passado (introduzir-se no tempo) para, então, discernir a validade dos pré-juízos. Não obstante, embora Apel ainda compartilhe com Gadamer que a compreensão exige a fusão de horizontes (da mediação entre o presente e o passado), observa que este postulado, por si só, não oferece uma compreensão crítico-reflexiva e não pode ser concebido como critério de validação para a compreensão, porque necessitaria de uma distância temporal.

Há, então, segundo Apel, a necessidade de um critério, válido metodologicamente, que atenda uma real e verdadeira compreensão, ou melhor, a necessidade de uma reflexão capaz de explicar e discutir questões universalmente válidas, de possibilidade e validade, que não possa se sustentar sem a reflexão pragmático-transcendental, o que poderia ocasionar um "esquecimento do logos". Para Apel, o postulado de Gadamer, segundo qual o indivíduo está munido de uma autopenetração (do espírito) reflexiva sobre sua vivência, parece introduzir uma concepção hermenêutica metodologicamente relevante. No entanto, ao pressupor que toda compreensão acontece de modo diferente, reduz o significado pleno de compreensão. Neste sentido, toda e qualquer situação histórica aciona uma interpretação diferente e, por isso, não é possível atingir uma compreensão melhor, ou seja, capaz de sustentar uma interpretação, entre os dialogantes, que seja sustentável e incontestável. Ainda mais, segundo Apel, Gadamer confere a cada interpretante a capacidade de compreender-se melhor, mas, para Apel, tal compreensão não adquire uma reflexão crítica sobre o seu caráter de verdade, ou seja, não há um questionamento sobre a objetivação da verdade, mas pela efetivação histórica, o que prevalece o dogmatismo (instituído nos pré-juízos). ${ }^{9}$

\footnotetext{
APEL, Karl-Otto. Transformação da Filosofia I, p. 52.

9 COSTA, Regenaldo da. Ética do Discurso e Verdade em Apel, p. 39-41. "Podemos dizer, então, com Apel, que se o intérprete não se considera com direito a julgar criticamente o que deve compreender e, portanto, não se acredita capaz de verdade, é porque ele não se situou do ponto de vista de uma hermenêutica filosófica, mas se aferrou a uma hermenêutica a serviço de uma fé dogmática". Ibid., p. 42.
}

12 Revista de Cultura Teológica - v. 20 - N. 80 - OUt/DEZ 2012 
A partir desta análise, Apel pretende demonstrar que uma hermenêutica normativa só pode consolidar-se pelo viés de uma concepção filosófica transcendental da compreensão, ou seja, por uma reflexão crítica do compreender, pautada pelo questionamento kantiano acerca das possibilidades e validade do conhecimento. ${ }^{10}$ Este critério remonta á validade e fundamento do conhecimento. Portanto, para Apel, toda compreensão abrange "o autor do sentido que há de ser compreendido, melhor do que este se compreende a si mesmo".11 Este legado de Gadamer é de suma importância para a hermenêutica. Mas para Apel, embora este legado seja relevante, perde sua força com Gadamer, ao sustentar que o entendimento sempre acontece de outra maneira, ou seja, sempre regido por novas interpretações. Por isso, Gadamer reduz a fundamentação de uma hermenêutica relevante para o pensar. ${ }^{12}$

\section{O GIRO PRAGMÁTICO-SEMIÓTICO}

O novo horizonte do pensamento filosófico, compreendido nos seus ditames de uma semiótica, portadora de signos, deve-se a Charles S. Peirce, com a descoberta de uma relação triádica, para o estatuto da cognição, em detrimento de uma relação bivalente. A cognição de algo como algo é fruto de uma interpretação, mediada por signos. Com isso, Apel, com Peirce, observa que a cognição não pode consolidar-se pelos dados sensórios, nem pela relação sujeito-objeto ou pela relação teoria e fatos, como também não pode construir-se por meio de conceitos, como em Kant (da síntese transcendental). ${ }^{13}$

Nesta perspectiva, segundo Peirce, como afirma Apel, a transformação semiótica do pensamento kantiano acontece em três grandes vertentes: a) Não há nenhuma cognição de algo como algo sem uma mediação sígnica real com base em veículos sígnicos materiais. Este postulado também se

10 CONTINA, Adela. Karl-Otto Apel: verdade e responsabilidade. In APEL, Karl-Otto. Teoría de la verdad y étca del discurso, p. 15.

11 COSTA, Regenaldo da. Ética do Discurso e Verdade em Apel, p. 43.

12 APEL, Karl-Otto. Transformação da Filosofia I, p. 54-55.

13 Id. Transformação da Filosofia II, p. 215. 
aplica aos índices, ícones e símbolos,${ }^{14}$ pois eles garantem a referência do discurso, como também integram os indivíduos às relações de semelhança da natureza. Aqui reside a transformação semiótica da epistemologia; b) Não há qualquer função de representação do signo para a consciência sem um mundo real, que em princípio precisa ser pensado como representável em aspectos, isto é, cognoscível em aspectos. Para Peirce, em nenhum momento este postulado pode ser negado, pois haverá sempre a necessidade de uma relação sígnica trivalente. Ao contrário, o processo cognitivo semiótico seria destruído. Para Peirce, a distinção kantiana entre o real cognoscível e a coisa-em-si não tem qualquer sustentabilidade, pois "ignora que a cognição, semioticamente entendida, tenha alcance tão amplo quanto a elaboração de hipóteses sensatas com anseio de verdade". ${ }^{15}$ Para Apel, este postulado é negado na medida que se despreza a consciência em favor de uma filosofia da linguagem, compreendida semioticamente. ${ }^{16}$ Aqui reside a transformação semiótica da crítica cognitiva; c) Não há nenhuma representação de algo como algo por meio de um signo sem que haja interpretação por um intérprete real. Não pode haver, segundo este postulado, um sujeito da consciência. Ao contrário, há um interpretante real, portador de signos e, com isso, a negação de uma consciência pura e a substituição de uma consciência objetual pela opinião formulável como interpretação dos signos. Aqui reside a transformação semiótica da crítica do sentido do real. ${ }^{17}$

Para Peirce, segundo Apel, o processo cognitivo kantiano, sustentado pela dedução transcendental, deve ser substituído pelo postulado de uma convicção última, sustentada por uma comunidade, pelo uso da concordância. A comunidade real, estruturada por um processo de interpretação e senso

14 Um Signo pode ser denominado Ícone, Índice ou Símbolo. O primeiro, é um signo que se refere ao Objeto que denota apenas em virtude de seus caracteres próprios, caracteres que ele igualmente possui que um tal Objeto realmente exista ou não. O segundo, é um signo que se refere ao Objeto que denota em virtude de ser realmente afetado por esse Objeto. Por isso, ele tem uma qualidade em comum com o objeto. O terceiro, é um signo que se refere ao Objeto que denota em virtude de uma lei, normalmente uma associação de ideias gerais que opera no sentido de fazer com que o símbolo seja interpretado como se referindo àquele objeto. É uma lei ou tipo geral. PEIRCE, Charles S. Semiótica, p. 5253.

15 APEL, Karl-Otto. Transformação da Filosofia II, p. 216.

16 CONTINA, Adela. Karl-Otto Apel: verdade e responsabilidade. In APEL, Karl-Otto. Teoría de la verdad y étca del discurso, p. 19.

17 APEL, Karl-Otto. Transformação da Filosofia II, p. 215-217. 
crítico da realidade em busca da verdade, não reduz o processo cognitivo a uma função empírica descritiva da comunidade.

O consenso postulado de maneira senso-crítica é a garantia da objetividade da cognição que surge em lugar da "consciência em geral" transcendental kantiana; ela funciona como um princípio regulativo que ainda está por ser realizado como ideal comunitário na comunidade real e através dela; e aí a incerteza quanto ao alcance factual do objetivo precisa ser substituído por um princípio ético de engajamento e de esperança: o princípio peirceano do "socialismo lógico". ${ }^{18}$

Em suma, tal como observa Apel,

Uma interpretação mais exata do pragmatismo semiótico de Peirce mostra que ele se adapta à lógica normativa da mediatização de teoria e praxis, fundada já em 1868, com vistas ao objetivo transcendental-filosoficamente postulado de um consenso de verdade em uma comunidade ilimitada dos cientistas. Esse processo de pesquisa teleológico transcendentalfilosoficamente postulado, no entanto, será tratado pelo Peirce do pragmaticismo como caminho para uma consumação prática da racionalização do universo por meio da formulação autocontrolada de "habits". O sujeito de tal formação, contudo, assim como os "habits" enquanto "logical intepretants", não deve ser reduzido a um objeto empírico das ciências sociais; e ele também não é uma consciência pura em geral, como na filosofia transcendental clássica de Kant (e ainda na de Husserl), mas sim uma comunidade real de experimentação e de interpretação, na qual se pressupõe ao mesmo tempo, como "telos", uma comunidade ideal ilimitada. Tal como seus signos e ações, essa comunidade é experienciável, mas não como um objeto da experiência, e sim como um meio intersubjetivo de acordo mútuo quanto às condições de possibilidade e de validade conceituais próprios às descrições e elucidações dos dados da observação. ${ }^{19}$

18 APEL, Karl-Otto. Transformação da Filosofia II, p. 215-217, p. 218.

19 Ibid., p. 225. 
No entanto, para Apel, embora Peirce represente o principal transformador da filosofia transcendental kantiana, ainda não foi possível, em sentido último, considerar uma transformação satisfatória. Pois Peirce ainda está prezo a um horizonte cientificista e, por isso, não é possível distinguir, com clareza, o processo de investigação da ciência natural e o processo do acordo comunicativo, dado pela interpretação com pretensão de validade. O próprio Peirce se convence, para Apel, que o acordo existe sobre o estado de coisas, dado pela experiência. ${ }^{20}$ Conforme Apel, Peirce "baseia a possível objetividade da ciência natural no processo histórico do acordo na comunidade de cientistas e este consenso, que corresponde à consciência transcendental em geral, é a garantia da objetividade". ${ }^{21}$ Neste sentido Apel afirma a necessidade de superação do cientificismo de Peirce, uma vez que a argumentação cientificista enfraquece ou ignora o diálogo entre os interpretantes de uma comunidade, o que pode desencadear em manipulação empírica em favor de fins propostos. Por isso, conforme Apel, a linguagem não pode ser ignorada numa comunidade de comunicação: ela é a "instituição das instituições", o meio autorreflexivo para o acordo ilimitado, a "metainstituição" de todos os possíveis acordos. A linguagem, enquanto veículo de comunicação, só pode proporcionar a interação entre os dialogantes, assim como acordos entre eles. ${ }^{22}$

Somente a comunidade ilimitada de comunicação, mediada pela linguagem, com pretensões de verdade e acordo, pode romper com o solipsismo e superar o cientificismo peirceano. Em tal cientificismo não há lugar para a pré-compreensão hermenêutica. Por isso, para Apel, o sujeito de interpretação participa de uma comunidade histórica em detrimento de uma comunidade interpretativa dos experiementadores.

\footnotetext{
20 Segundo Apel, Peirce, com a Publicação The Fixation of Belief e How to Make Our Ideas Clear, parece consolidar o processo cognoscitivo não mais numa comunidade de investigadores, mas no processo de comportamento do real, como ele se apresenta na sua regularidade. Dessa maneira, Peirce prescreve a fixação de uma convicção construída pela observação dos hábitos comportamentais.

21 COSTA, Regenaldo da. Ética do Discurso e Verdade em Apel, p. 61.

22 COSTA, Regenaldo da. Ética do Discurso e Verdade em Apel, p. 62.
} 


\section{A TRANSFORMAÇÃO DA FILOSOFIA TRANSCENDENTAL}

Das hermenêuticas de Gadamer e Heidegger e da semiótica de Peirce, ainda que criticadas, Apel extrai elementos vitais para o seu postulado filosófico, pois essas correntes "recorrem ao a priori da linguagem e à dependência aí explícita do pensar e do conhecer em relação ao acordo intersubjetivo, o que implica a radical superação"23 do solipsismo metódico. Isto quer dizer, a superação de um sujeito de consciência capaz de pensar, conhecer e validar normas para o seu agir, independente de uma comunidade de argumentantes.

Segundo Apel, a semiótica de Peirce, sustentada pela relação triádica dos signos, possibilita a condição necessária da interpretação do mundo, como também a condição de todo pensar e pretensão de verdade. Os signos surgem como uma mediação segura entre os homens e os objetos; sua função pode ser compreendida como possibilidade de descrição, interpretação e conhecimento das coisas, intersubjetivamente válidas. Esta função adquire um sentido transcendental.

Por isso, essas correntes, discutidas por Apel, superam o estatuto de uma linguagem pré-linguística (como em Locke, ao afirmar que o pensar depende de private ideas; e em Kant, de uma consciência geral), sustentada pela consciência capaz de conhecer e eleger verdades para todos, sem a mediação da linguagem como instância segura de acordos entre os falantes de uma comunidade de comunicação. Segundo Apel, embora Kant - na Crítica do Juízo - tenha se aventurado a superar o solipsismo, ao falar do "sentido comum" e da "aprovação dos outros", continuou prezo ao sujeito, pois "os outros" nada mais representa que um critério de verdade do sujeito, ditado pela razão, a fim de validar um conhecimento objetivo. ${ }^{24}$

Apel, então, entende que somente recorrendo à interpretação semiótica-transcendental ou pragmático-transcendental poder-se-á falar de uma superação da filosofia transcendental clássica, ou seja, de superação do solipsismo metódico. Medida que somente se torna possível com o recurso ao acordo comunicativo, como instância necessária de todo pensar e conhecer, mediado pela linguagem histórica, constituída como um logos universal da filosofia.

\footnotetext{
3 Ibid., p. 157.

24 COSTA, Regenaldo da. Ética do Discurso e Verdade em Apel, p. 157.
} 
Com a descoberta do discurso, Apel irá consolidar uma filosofia transcendental em detrimento dos pressupostos metafísicos, sobretudo na doutrina dos dois mundos. Dessa forma, a fundamentação pragmático-transcendental somente poderá acontecer por uma estrita autorreflexão. Nesta autorreflexão, "cada um de nós poderá descobrir não só as condições de possibilidade do discurso, mas também que essas condições são transcendentais, isto é, intransponíveis e incontestáveis e, portanto, necessárias, universais e últimas". ${ }^{25}$

Se a linguagem passa a ser o logos universal da filosofia, então o a priori da linguagem, enquanto a priori da argumentação e, por sua vez, o a priori da comunidade de comunicação, enquanto comunidade a priori de argumentação, passam a ser instância última de validade intersubjetiva, pois, deste modo, o a priori da argumentação, imanente à linguagem, é o ineliminável, o irretrocedível para o filosofar, e tem que ser tomado como condição de possibilidade da validade universal das intenções filosóficas. ${ }^{26}$

Com isso, Apel pressupõe necessário o a priori da argumentação, não podendo deixar de ser negado pelos falantes, a fim de evitar uma autocontradição performativo-proposicional, ${ }^{27}$ distintivo tal da transformação pragmático-transcendental da filosofia. Com o impedimento da autocontradição performativo-proposicional, critério basilar da diferença transcendental da razão, incorporou-se as conquista da linguagem hermenêutica e da pragmática linguística e, com isso, a consideração da dimensão semântica e da pragmático-linguística, que possibilita a pretensão de verdade e validade. Para Apel, a condição performativa indica uma possibilidade de pensamento, como via de explicitação das pretensões de validade de uma sentença. Dessa forma, na pragmática transcendental, todo saber reflexivo ganha forma de preposições, com pretensão de universalidade e, por isso, são autorreferentes: "nosso saber semiótico-transcendental sobre a função

25 OLIVEIRA, Manfredo A. de. Correntes Fundamentais da Ética Contemporânea, p. 169.

26 COSTA, Regenaldo da. Ética do Discurso e Verdade em Apel, p. 158.

27 "Essa contradição não se refere a seguimentos particulares de uma afirmação (ou daquela norma) e as condições que the possibilitariam ser afirmada. Seria contraditório refutar a ideia da mente comunicativa, uma vez que, como premissa daquela afirmação particular, pode-se distinguir tanto a ideia da comunicação como a ideia concernente à possibilidade de fundamentação filosófica, ou seja, a ideia da razão (Vernunft)." MíloVIC, Míroslav. Filosofia da Comunicação, p. 242. 
atual do signo ou da linguagem não é outra coisa que a transposição transcendental do saber reflexivo, que assume a expressão linguística através da parte performativa autorreferencial dos atos de fala constatativos". ${ }^{28}$ Não obstante, a referência semântica das proposições em nenhum momento pode isentar-se do contexto pragmático do uso dos signos. Ao contrário, uma semântica puramente abstrativa nada mais tornaria o pensamento propenso a um sofisma abstrativo, incapaz de compreender o sentido dos signos da linguagem.

Portanto, a filosofia pragmática transcendental tem, fundamentalmente, dois postulados, a saber: "demonstrar que uma fundamentação filosófica é possível e, em segundo lugar, demonstrar, a partir dessa possibilidade, a obrigatoriedade das normas". ${ }^{29}$ Portanto, o ponto singular da transformação da filosofia transcendental consiste na substituição da síntese transcendental da percepção de Kant pela síntese transcendental interpretativa, mediada pela linguagem, dada numa comunidade comunicativa de interpretação: ao invés da consciência, o princípio regulativo da formação crítica do consenso em uma comunidade. ${ }^{30}$

\section{CONCLUSÃO}

O pensamento crítico de Apel, diante da filosofia clássica, permitiu a fundação de um novo horizonte filosófico: a constituição de uma filosofia pragmático-transcendental, que tem a linguagem como medium de todo pensar, em busca da verdade e validação das proposições tomadas em consenso pela comunidade ilimitada de comunicação. Tal perspectiva foi suscitada com o giro hermenêutico-linguístico e semiótico-pragmático, fundamentalmente com os expoentes do pensamento de Heidegger, Gadamer e Peirce. No entanto, tais pensadores não esgotam o referencial de suporte filosófico para a transformação da filosofia transcendental kantiana, como abordada por Apel. Não obstante, o pensamento de Apel parte de Kant e,

28 APEL, Karl-Otto. La Sémiotique transcendentale et les paradigmes de La prima philosophia. Em Revue de Métaphysique et Morale. Arnand Colin Éditeur, Paris, 1987, p.150. Apud COSTA, Regenaldo da. Ética do Discurso e Verdade em Apel, p. 158.

29 MílOVIC, Míroslav. Filosofia da Comunicação, p. 228.

30 OLIVEIRA, Manfredo A. de. Reviravolta linguístico-pragmática na filosofia contemporânea, p. 278. 
por isso, ele conserva o legado transcendental kantiano, mas numa vertente de fundamentação última, ou seja, como via instransponível de todo pensar e que requer o mútuo entendimento entre os interpretantes de uma comunidade de comunicação. Apel, embasado pela tríade semiótica, substitui o eu penso de Kant pelo nós argumentamos. Portanto, Apel não abandona a "memória" filosófica, mas a supera na tentativa de fundamentar o seu postulado ético (Apel tem sólidas discussões com Wittgenstein, Weber, Carnap e outros pensadores relevantes para o pensamento filosófico, assim como traça um duelo com o solipsismo metódico, o positivismo e racionalismo). Em suma, a reflexão aqui realizada visou apenas pontuar, por alguns pensadores, a perspectiva filosófica de superação da filosofia transcendental kantiana, o que não esgota $o$ entrave de Apel com outros pensadores que também constituem os pilares para o pensar da filosofia transcendental.

\section{BIBLIOGRAFIA}

APEL, Karl Otto. Teoría de la verdad y ética del discurso. Barcelona: Paidos, 1998.

- Transformação da Filosofia I - Filosofia analítica, semiótica, hermenêutica. São Paulo: Loyola, 2000.

- Transformação da Filosofia II - O a priori da comunidade de comunicação. São Paulo: Loyola, 2000.

COSTA, Regenaldo. Ética do Discurso e Verdade em Apel. Belo Horizonte: Del Rey, 2002.

HABERMAS, Jürgen. Um maestro con sensibilidad hermenêutica. In Anthropos, 183, marzo-abril, 1999.

MíLOVIC, Míroslav. Filosofia da Comunicação - Para uma Crítica da modernidade. Trad. Verrah Chamma. Brasília: Plano Editora, 2002.

OLIVEIRA, Manfredo Araújo de. Correntes fundamentais da ética contemporânea. Petrópolis: Vozes, 2000.

Reviravolta linguístico-pragmática. São Paulo: Loyola, 1996.

PEIRCE, Charles S. Semiótica. Trad. José Teixeira Coelho Neto. São Paulo: Perspectiva, 1995. 